\title{
Bioequivalence of Two Prolonged-Release Diclofenac Sodium Formulations in Healthy Volunteers: A Randomized, Crossover, Double-Blind Study
}

González-Delgado $C A^{1}$, Padrón-Yaquis $\mathrm{AS}^{2^{*}}$, Jiménez-Rodríguez $\mathrm{D}^{3}$, Cazanave-Guarnaluce $\mathrm{D}^{2}$, $A$ lejo-Cisneros $\mathrm{PL}^{2}$, Festary-Casanovas $\mathrm{T}^{3}$,

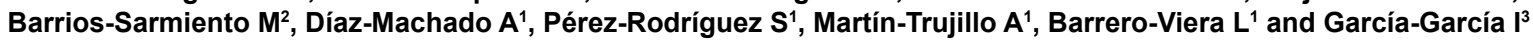

${ }^{1}$ National Centre for Toxicology, Carlos J. Finlay University Hospital, Havana, Cuba

${ }^{2}$ Analytical Group, Control of Quality Direction, Centre for Pharmaceutical Research and Development, Havana, Cuba

${ }^{3}$ Clinical Trials Group, Research Direction, Centre for Pharmaceutical Research and Development, Havana, Cuba

\begin{abstract}
Background: The implementation of generic drug development programs constitutes a basic component of the global health policy. The aim of this work is to determine the existence of bioequivalence between two prolongedrelease diclofenac sodium formulations in healthy volunteers.

Methods: A phase I, randomized, crossover, double-blind clinical trial was conducted where pharmacokinetics in plasma and biological safety of Voltaren Retard $^{\circledR}$ (reference formulation) and a generic prolonged-release Cuban diclofenac sodium formulation were compared. The sampling period was 24 hours, with a washout time of 15 days between each one. All subjects received, orally, a single dose of $100 \mathrm{mg}$ (one tablet) of the corresponding formulation in each period.

Results: Thirty-six volunteers, the half women, with a mean age of 33 years were included. White skin subjects were $56 \%$. The quantification of diclofenac sodium in plasma by HPLC demonstrated a high similitude between formulations. The mean values of the pharmacokinetic parameters were: $\mathrm{AUC}_{24}\left(4924 \mathrm{vs} .4928 \mathrm{ng} \cdot \mathrm{h} / \mathrm{mL}\right.$ ), AUC $\mathrm{Cinf}_{\mathrm{inf}}$ (5046 vs. $5054 \mathrm{ng} \cdot \mathrm{h} / \mathrm{mL}), \mathrm{C}_{\max }\left(1047\right.$ vs. $1042 \mu \mathrm{g} / \mathrm{mL}$ ), $\mathrm{t}_{1 / 2} 2.25$ vs. $2.25 \mathrm{~h}$ ), Median $\mathrm{T}_{\max }$ was 2 hours for both formulations. The preparations could be considered as bioequivalent according to ANOVA and $90 \% \mathrm{Cl}$ analysis. No formulation, period, sequential and residual effects were detected. The adverse events were mild, well tolerated, with a low frequency of onset. The most frequent events were hypertension, headache and increase in transaminases and urea values, registered in less than $10 \%$ of the subjects.
\end{abstract}

Conclusion: Cuban prolonged-release diclofenac sodium formulation was bioequivalent with the commercial reference formulation Voltaren Retard ${ }^{\circledR}$.

Keywords: Diclofenac sodium; Prolonged-release formulation; Bioequivalence; Pharmacokinetics; Healthy volunteers

\begin{abstract}
Abbreviations: ALT: Alanine Aminotransferase; AST: Aspartate Aminotransferase; AUC: Area Under the Curve; CI: ConfidenceIntervals; $\mathrm{C}_{\max }$ : Maximum Observed Plasma Concentration; GGT: GammaGlutamyltransferase; Hgb: Hemoglobin; HPLC: High Resolution Liquid Chromatography; HPMC: Hydroxypropyl Methylcellulose; NSAIDs: Non-steroidal Anti-inflammatory Drugs; PK: pharmacokinetics; $\mathrm{T}_{\max }$ : Time of Maximum Observed Concentration; $t_{1 / 2}$ : Terminal Half-life; WHO: World Health Organization; WL_90_Lower: Lower Limit of an 90\% Classical Confidence Interval; WL_90_Upper: Upper Limit of an $90 \%$ Classical Confidence Interval; $\lambda$ : Lambdaz (First Order Rate Constant Associated with the Terminal (log-linear) Portion of the Curve).
\end{abstract}

\section{Background}

The incorporation in the pharmaceutical market of generic drugs has a clear impact on the public health, due to the cost of a treatment using these drugs is usually significantly lower than the treatment with the innovative or brand product and it favors the access or availability of essential or first-line drugs to the population that needs them.

Bioequivalence studies are a practical alternative to ensure biological equivalence of a generic drug with the innovator, taking into account the difficulty to evaluate directly the therapeutic equivalence by complex, prolonged and expensive studies. It is only necessary to show that the profile of plasma concentrations versus time curve of the active ingredient contained in the generic formulation is equivalent to the one observed with the innovative product.

Diclofenac sodium is a phenylacetic derivative which was specifically created as an anti-inflammatory drug. It is approved by the Food and Drug Administration (FDA) for the long-term symptomatic treatment of rheumatoid arthritis, osteoarthritis and ankylosing spondylitis. Its potency is substantially higher than that of other non-steroidal antiinflammatory drugs (NSAIDs), such as indomethacin and naproxen among others. It accumulates in the synovial fluid which explains the duration of the therapeutic effect, which is considerably longer than its plasma half-life. The current daily dose for the treatment of such diseases is from 100 to $200 \mathrm{mg}$ divided into several fractions [1-4].

*Corresponding author: Padrón-Yaquis AS, Centre for Pharmaceutical Research and Development (CIDEM), Ave. 26 and Puentes Grandes, No. 1605, Nuevo Vedado, Havana 10600, Cuba, Telephone: 53-7-8811844; Ext: 102; Fax: 53-7-8335556; E-mail: alejandro.padron@cidem.cu

Received September 22, 2017; Accepted October 30, 2017; Published November 11, 2017

Citation: González-Delgado CA, Padrón-Yaquis AS, Jiménez-Rodríguez D, Cazanave-Guarnaluce D, Alejo-Cisneros PL, et al. (2017) Bioequivalence of Two Prolonged-Release Diclofenac Sodium Formulations in Healthy Volunteers: A Randomized, Crossover, Double-Blind Study. J Bioequiv Availab 9: 555-560. doi: 10.4172/jbb.1000361

Copyright: @ 2017 González-Delgado CA, et al. This is an open-access article distributed under the terms of the Creative Commons Attribution License, which permits unrestricted use, distribution, and reproduction in any medium, provided the original author and source are credited. 
Prolonged-release formulations make possible to prescribe the drug in a single daily dose or twice a day, which greatly simplifies long-term treatment and produces a substantial improvement in patient's compliance [5]. Retard diclofenac sodium formulation is useful in patients in whom a daily dose of 75 or $100 \mathrm{mg}$ is sufficient according to the clinical picture. From the pharmaceutical and therapeutic perspectives, this formulation reduces fluctuations in plasma concentrations which may result in a more continuous effect. Additionally, peak concentrations are lower and, consequently, the incidence and intensity of adverse effects is reduced $[1,4]$.

A Cuban $100 \mathrm{mg}$ prolonged-release diclofenac sodium formulation was developed at the Centre for Pharmaceutical Research and Development (CIDEM, in Spanish). To demonstrate its bioequivalence with another similar, commercially available reference preparation, their pharmacokinetic and safety profiles were compared.

\section{Materials and Methods}

A randomized, crossover, double-blind study with a 15days washout period was carried out at the National Centre for Toxicology, Havana, Cuba, which is a certified reference unit for bioavailability and bioequivalence studies. The clinical protocol was approved by the institutional ethics committee of the National Centre for Toxicology in Havana. All procedures performed in healthy volunteers were in accordance with the ethical standards of this committee and with the 1964 Helsinki declaration and its later amendments. The trial was also approved by the Cuban Centre for the Control of Drugs, Equipment \& Medical Devices (reference number: $1417 / 05.005 .11 . \mathrm{M})$. Prior to any test, all volunteers gave their written informed consent to participate.

\section{Subjects}

Cuban healthy individuals from both genders, aged between 18 and 50 years, with a body mass index (BMI) between 18 and $29.9 \mathrm{~kg} /$ $\mathrm{m}^{2}$, were included. They were considered healthy if they had no history of chronic diseases, did not suffer any acute illness in the previous 7 days, had no symptoms or signs at the physical examination and laboratory tests, and were negative to HIV and hepatitis B and C virus infections markers in serum. Exclusion criteria were: women who are pregnant or breastfeeding, hypersensitivity to aspirin or other NSAIDs, history of alcoholism, treatment with any drug in the previous 15 days, surgical intervention in the previous six months, blood donations in the previous three months and participation in a clinical trial during the prior six months. They were withdrawn from the trial if they abandoned voluntarily, had severe or more than five-day mild adverse reactions, or if any exclusion criteria arose.

\section{Prolonged-release diclofenac sodium formulations}

Formulation A (reference formulation) was Voltaren Retard 100 mg lacquered tablets (Novartis Pharmaceuticals, Basel, Switzerland). Each tablet contains the medicinal ingredient diclofenac sodium and non-medicinal ingredients: black ink, carnauba wax, cellulose compounds, cetyl alcohol, colloidal silicon dioxide, hypromellose, magnesium stearate, polysorbate 80 , povidone, red iron oxide, sucrose, talc, titanium dioxide. Formulation B (test formulation, CIDEM, Havana, Cuba) contains $100 \mathrm{mg}$ diclofenac sodium, $60 \mathrm{mg}$ HPMC, $120.5 \mathrm{mg}$ lactose, $15 \mathrm{mg}$ polyvinylpyrrolidone $\mathrm{K}-25,4.5 \mathrm{mg}$ magnesium stearate, solvents and covering components for each tablet.

\section{Study design}

Subjects were distributed according to a computer-generated simple random number list to two treatment sequences ( $\mathrm{AB}$ or $\mathrm{BA})$ with the same number of individuals each one. After overnight fasting, they received, orally, $100 \mathrm{mg}$ (one tablet) of one of the Diclofenac sodium preparations (A or B), in a crossover design with a 15-days washout period between treatments. This dose, commonly used for the reference preparation in the clinics, was given together with a glass of water $(240 \mathrm{~mL})$ that was ingested completely.

The study was double blinded. As the presentation of the formulations differed, each was placed individually, according to the random distribution list, in opaque plastic bottles that were labeled with the subject's inclusion number by the nurse responsible for the administration of the products. Therefore, neither researchers nor the volunteers could identify the formulation. The same nurse administered each formulation directly in the mouth of each subject taking care that he does not see. She did not perform any other role in the trial.

During each period, individuals were hospitalized during 24 hours after administration under strict medical supervision. They could not ingest water one hour before or after administration of the tablets and not eat food and remain at rest during the first four hours of the study. Concomitant treatments could be administered to mitigate adverse events, after medical consent. None of these treatments could affect the results by interactions or direct effects on the tested variables.

\section{Laboratory and clinical evaluations}

For diclofenac sodium measurements, blood samples $(5 \mathrm{~mL})$ were obtained by venipuncture before and $0.5 ; 0.75 ; 1 ; 1.33 ; 1.66 ; 2 ; 2.50 ; 3$; $4 ; 6 ; 8 ; 10 ; 12$ and 24 hours after oral administration. Plasma samples were distributed into specific vacutainers (Vacuette, Greiner Bio-One International $\mathrm{GmbH}$ ) to obtain plasma after centrifugation at 2000 rpm during 10 minutes. The separated plasma samples were stored at $-20^{\circ} \mathrm{C}$ until testing.

Diclofenac sodium was quantified in human plasma by High Resolution Liquid Chromatography (HPLC), using liquid-liquid extraction to process samples. The EuroChrom 2000 chromatography management software was used to control the HPLC system which comprised a K-1001 HPLC pump, a K-2600 UV variable detector, and the Basic Marathon automatic injector (Knauer, Berlin, Germany). The UV detector was used to monitor drug wavelength $(282 \mathrm{~nm})$. The mobile phase was methanol and phosphate buffer $(56: 44, \mathrm{v} / \mathrm{v})$ at a flowrate of $0.4 \mathrm{~mL} / \mathrm{min}$. A LiChrosorb RP-18 reversed-phase column, 250 $\mathrm{mm} \times 4 \mathrm{~mm}$ (ID) with $4 \mu \mathrm{m}$ particle size was used.

Subjects were regularly checked for vital signs and symptoms during the whole study. Adverse events were considered severe in case of patient's death, threaten patient's life, require or prolong hospitalization or produce a significant or persistent disability. The medical terminology for adverse events and their classification of intensity (1-5 grades) was applied according to the Common Terminology Criteria for Adverse Events [6]. The causality assessment included the terms very probable/certain, probable (likely), possible, unlikely, not related or unassessable/unclassifiable, according to WHO criteria for causality [7].

Additionally, blood samples were taken for routine hematological and biochemical determinations before and after treatment at each period. Hematological counts (hemoglobin, hematocrit, platelet count, total and differential leukocyte counts) and blood chemistry (glucose, 

of Two Prolonged-Release Diclofenac Sodium Formulations in Healthy Volunteers: A Randomized, Crossover, Double-Blind Study. J Bioequiv Availab 9: 555-560. doi: 10.4172/jbb.1000361

cholesterol, creatinine, urea, hepatic enzymes, total proteins, total bilirubin) were done according to usual clinical laboratory procedures at the Clinical Laboratory of the Centre for Medical-Surgical Research, Havana, Cuba, a laboratory certified by the Cuban Regulatory Agency. Advanced automated analyzers (Mindray, Shenzhen, China; Cobas, Roche Diagnostics, Basel, Switzerland) were used for these purposes. These evaluations were done blindly regarding the subjects' group allocation.

\section{Data analysis}

The drug disposition data analysis was performed per individual by a non-compartmental method with a combined linear/log - linear trapezoidal rule approach. The linear trapezoidal rule was used up to peak level and the logarithmic trapezoidal rule thereafter. The first-order rate constant associated with the curve terminal (log linear) portion $(\lambda)$ and terminal half-life $\left(t_{1 / 2}\right)$ were estimated by linear regression of the included terminal data points. Time-to-peak values $\left(\mathrm{T}_{\max }\right)$ were determined directly from the experimental data as the time in which the maximum observed level is reached $\left(\mathrm{C}_{\max }\right)$ considering the entire curve. Area under the plasma concentrationtime curve from 0 to 24 hours $\left(\mathrm{AUC}_{24}\right)$ was calculated using the linear/log linear trapezoidal rule. AUC extrapolated to infinity $\left(A C_{i n f}\right)$ was computed based on the last predicted value from the linear regression performed to estimate $\lambda$ and $t_{1 / 2}$. The WinNonlin professional software (Version 5.1, Pharsight Inc., 2005, NC, USA) was used for these purposes.

Data were double entered and validated and then imported into SPSS for Windows (version 15.0, IBM Analytics 2006, Armonk, North Castle, NY, USA) and Epidat (version 3.1, Directorate General of Public Health (Xunta de Galicia) 2006, Santiago de Compostela, Spain) for further analysis. Continuous variables were expressed as mean \pm standard deviation (SD) or median \pm interquartile range $(\mathrm{QR})$ and minimum and maximum values (range). With these variables a normality analysis (KolmogorovSmirnov's test or Shapiro Wilk's test) and homogeneity of variance (Levene's test) were carried out. Pharmacokinetic parameters were analyzed by the parametric method for crossover designs (ANOVA, proposed by Grizzle) [8]. The $90 \%$ confidence intervals ( $90 \%$ CI) for the difference between pharmacokinetic parameters were calculated according to Westlake [9]. Vital signs and clinical laboratory variables were treated using paired analysis (Student's $t$ test or Wilcoxon's test) depending on the normality assumption, taking into account Bonferrony's adjustment for multiple comparisons. Significance level chosen was 0.05 . Categorical variables were given as frequencies and percentages.

\section{Results}

Thirty-six apparently healthy subjects were selected among a universe of 81 volunteers who presented themselves to the call for participating in the trial. The demographic and baseline characteristics of the subjects, grouped by sequence of treatment, are shown in (Table 1). Groups were homogeneous regarding each characteristic. The mean age was 33 years and they weighed around $67 \mathrm{~kg}$ and were $168 \mathrm{~cm}$ tall. The BMI was between 18.7 and $25.3 \mathrm{~kg} / \mathrm{m}^{2}$. White skin subjects slightly prevailed (56\%). There was equal number of female and male subjects. The presence of toxic habits was reduced in both groups.

One subject ( $\mathrm{AB}$ sequence) presented moderate acute gastroenteritis at the beginning of the second period. For this reason, he did not receive the dose (test formulation) corresponding to this period. He was excluded from the pharmacokinetic analyses being only taken into account for safety. The rest of the individuals fulfilled with the treatment and evaluations as previewed.

\section{Pharmacokinetic analysis}

The average diclofenac sodium concentration profiles obtained for the formulations were quite similar, with overlapping curves (Figure 1). At 12 hours after the injection, plasma concentrations had returned closely to the initial values, and 12 hours later levels were almost undetectable. So, the $\mathrm{AUC}_{24}$ obtained covered in all cases more than $95 \%$ of the AUC extrapolated to infinite. Most of the individual concentrations surpassed $1000 \mathrm{ng} / \mathrm{mL}$, determined by HPLC, with both formulations.

The pharmacokinetic parameters estimated from plasma profiles and were shown in (Table 2). The values of the central trends of every parameter as well as the low deviations obtained were very similar with both formulations. Clearly, none of the differences between the means of any parameter exceeds the clinically significant level of $20 \% . \mathrm{T}_{\max }$ and $\mathrm{t}_{1 / 2}$ values were 2.0 and 2.3 hours, respectively, with both formulations. For these parameters, overall ranges were $1.66-2.5 \mathrm{~h}$ and $1.60-3.67$ $\mathrm{h}$, respectively. Meanwhile, 1047 and $1042 \mathrm{ng} / \mathrm{mL}$ of $\mathrm{C}_{\max }$ was reached for reference and test formulation, respectively. The mean AUC values both to the last time and to infinity, were around $5000 \mathrm{ng} \cdot \mathrm{h} / \mathrm{mL}$.

The verification of the normality of the intra and inter-individual residues, as well as the independence between them was preliminarily satisfied. The analysis with the relevant parameters $\mathrm{C}_{\max }$ and $\mathrm{AUC}_{24}$, logarithmically transformed, proved that the effects of the sequence, period and formulation were not significant. Only a subject within sequence effect was detected indicating variability between individuals (Table 3). No residual (carryover) effect from the first treatment period onto the second period diclofenac sodium concentration values was found.

\begin{tabular}{|c|c|c|c|c|}
\hline \multicolumn{2}{|c|}{ Characteristic } & $\begin{array}{c}\text { AB sequence } \\
N=18\end{array}$ & $\begin{array}{c}\text { BA sequence } \\
\qquad N=18\end{array}$ & $\begin{array}{l}\text { Total } \\
\mathrm{N}=36\end{array}$ \\
\hline \multicolumn{2}{|c|}{ Age (years) } & $31 \pm 10(18-50)$ & $35 \pm 8(21-50)$ & $33 \pm 8(18-50)$ \\
\hline \multicolumn{2}{|c|}{ Weight (Kg) } & $63 \pm 10(49-80)$ & $71 \pm 12(50-94)$ & $67 \pm 11(49-94)$ \\
\hline \multicolumn{2}{|c|}{ Height $(\mathrm{cm})$} & $166 \pm 9(149-181)$ & $170 \pm 9(150-184)$ & $168 \pm 9(149-184)$ \\
\hline \multicolumn{2}{|c|}{ Body Mass Index } & $24.5 \pm 7.3(18.7-25.3)$ & $24.4 \pm 2.9(19.5-30.0)$ & $24.4 \pm 5.5(18.7-25.3)$ \\
\hline \multicolumn{2}{|c|}{ Male gender } & $8(44.4 \%)$ & $10(55.6 \%)$ & $18(50.0 \%)$ \\
\hline \multirow{2}{*}{ Skin color } & White & $12(66.7 \%)$ & $8(44.4 \%)$ & $20(55.6 \%)$ \\
\hline & Non-white & $6(33.3 \%)$ & $10(55.6 \%)$ & $16(44.4 \%)$ \\
\hline \multicolumn{2}{|c|}{ Smoke } & $5(27.8 \%)$ & $6(33.3 \%)$ & $11(30.6 \%)$ \\
\hline \multicolumn{2}{|c|}{ Alcohol (occasionally) } & $1(5.6 \%)$ & -- & $1(2.8 \%)$ \\
\hline
\end{tabular}

Data are reported as mean \pm standard deviation (range) or number of patients (\%).

Table 1: Demographic and baseline characteristics of the groups of treatment. 
Citation: González-Delgado CA, Padrón-Yaquis AS, Jiménez-Rodríguez D, Cazanave-Guarnaluce D, Alejo-Cisneros PL, et al. (2017) Bioequivalence of Two Prolonged-Release Diclofenac Sodium Formulations in Healthy Volunteers: A Randomized, Crossover, Double-Blind Study. J Bioequiv Availab 9: 555-560. doi: 10.4172/jbb.1000361

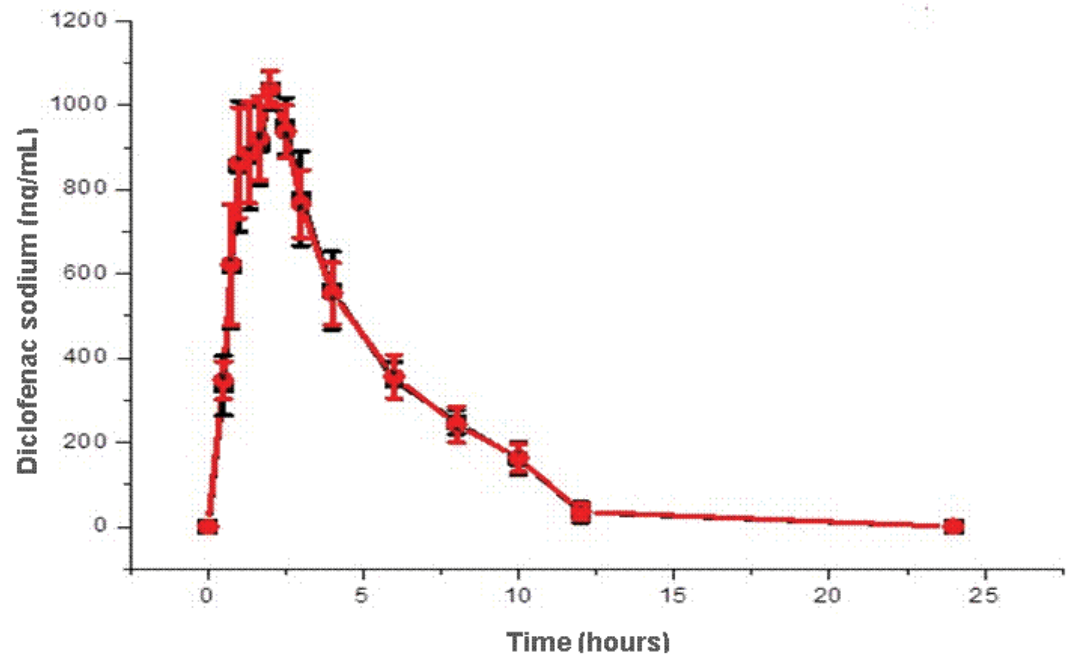

Figure 1: Average diclofenac sodium concentration in plasma. Data correspond to 35 healthy volunteers who received 100 mg of Voltaren Retard ${ }^{\circledR}$ (black line) and $100 \mathrm{mg}$ of Cuban prolonged-release diclofenac sodium formulation (red line). Standard deviations are also shown at each time.

\begin{tabular}{|c|c|c|}
\hline Parameter & Formulation A N=35 & Formulation B N=35 \\
\hline Tmax $(\mathrm{h})$ & $2.0 \pm 0.0(2.0-2.5)$ & $2.0 \pm 0.0(1.66-2.5)$ \\
\hline $\mathrm{Cmax}(\mathrm{ng} / \mathrm{mL})$ & $1047 \pm 40(982-1137)$ & $1042 \pm 44(923-1115)$ \\
\hline $\mathrm{AUC}_{24}(\mathrm{ng} \cdot \mathrm{h} / \mathrm{mL})$ & $4924 \pm 186(4543-5389)$ & $0.31 \pm 0.05(0.23-0.43)$ \\
\hline$\lambda\left(\mathrm{h}^{-1}\right)$ & $0.31 \pm 0.04(0.19-0.39)$ & $2.28 \pm 0.35(1.60-3.05)$ \\
\hline $\mathrm{t}_{1 / 2}(\mathrm{~h})$ & $2.25 \pm 0.34(1.77-3.67)$ & $5054 \pm 239(4350-5462)$ \\
\hline $\mathrm{AUC}_{\text {inf }}(\mathrm{ng} \cdot \mathrm{h} / \mathrm{mL})$ & $5046 \pm 253(4667-5965)$ & \\
\hline
\end{tabular}

Data are reported as mean \pm standard deviation (range), excepting $T_{\max }$ expressed as median \pm interquartile range (range).

Table 2: Pharmacokinetic parameters calculated from the diclofenac sodium concentrations in plasma. Descriptive analysis.

\begin{tabular}{|c|c|c|c|c|c|c|}
\hline Parameter & Effect & Sum of squares & Degrees of freedom & Mean sum of squares & $\mathbf{F}$ & $\mathbf{P}$ \\
\hline \multirow{5}{*}{$\ln \left(C_{\max }\right)$} & Sequence & 0.007364 & 1 & 0.007364 & 12.12 & 0.141 \\
\hline & Subject & 0.083196 & 33 & 0.002521 & 4.15 & 0.0001 \\
\hline & Period & 0.000177 & 1 & 0.000177 & 0.29 & 0.593 \\
\hline & Formulation & 0.000382 & 1 & 0.000382 & 0.63 & 0.434 \\
\hline & Residual & 0.020051 & 33 & 0.000608 & & \\
\hline \multirow{5}{*}{$\ln \left(\mathrm{AUC}_{24}\right)$} & Sequence & 0.001153 & 1 & 0.001153 & 0.72 & 0.401 \\
\hline & Subject & 0.112125 & 33 & 0.003398 & 2.13 & 0.017 \\
\hline & Period & 0.000604 & 1 & 0.000604 & 0.38 & 0.543 \\
\hline & Formulation & 0.000122 & 1 & 0.000122 & 0.08 & 0.783 \\
\hline & Residual & 0.052627 & 33 & 0.001595 & & \\
\hline
\end{tabular}

Table 3: Analysis of variance (ANOVA) for the logarithm of the maximum plasma concentrations and AUC until the last experimental time.

The $90 \%$ CI for the ratio of the means of the parametric model satisfied the bioequivalence condition between test and reference formulation for both PK parameters. Both intervals included the $100 \%$ (Table 4).

\section{Safety analysis}

Adverse events were recorded during both study periods. Nineteen subjects $(52.8 \%)$ presented at least one undesirable clinical or hematological manifestation. Nineteen types of adverse events were recorded, nine during clinical examinations and 10 identified during the monitoring of hematological and biochemical parameters. There were 12 types of events (63.2\%) with Formulation A and 11 (57.9\%) with Formulation B (Table 5). Just one volunteer had the same event (arterial hypertension) with both formulations.
Arterial hypertension and headache were the most frequent systemic adverse events, but only recorded in two or three subjects after having received one or the other formulation. Other gastrointestinal, cardiovascular o flu-like events were observed in a single subject. The increase in liver enzymes and urea levels were the most frequent laboratory alterations, but also recorded in few individuals (Table 5).

There were 38 event reports, 20 with Formulation A and 18 after having received Formulation B (Table 6). Of these, 20 reports were laboratory values outside reference ranges. Non-severe adverse events were recorded. Events were mostly (89.5\%) classified as grade 1 (mild). Only four events (flu-like syndrome, acute gastroenteritis, acidity and pyrosis), all of them after the administration of the reference formulation, were classified as grade 2 (moderate). The acute gastroenteritis was characterized by vomiting, diarrhea, fever, headache 
Citation: González-Delgado CA, Padrón-Yaquis AS, Jiménez-Rodríguez D, Cazanave-Guarnaluce D, Alejo-Cisneros PL, et al. (2017) Bioequivalence of Two Prolonged-Release Diclofenac Sodium Formulations in Healthy Volunteers: A Randomized, Crossover, Double-Blind Study. J Bioequiv Availab 9: 555-560. doi: 10.4172/jbb.1000361

\begin{tabular}{|c|c|c|c|c|}
\hline \multirow{2}{*}{ Parameter } & \multicolumn{2}{|c|}{ Confidence intervals } & \multicolumn{2}{|c|}{ Bioequivalence limits } \\
\cline { 2 - 5 } & WL_90_Lower & WL_90_Upper & Lower & Upper \\
\hline $\operatorname{In}\left(\mathrm{C}_{\max }\right)$ & 98.8 & 101.2 & 80.0 & 125.0 \\
\hline $\ln \left(\mathrm{AUC}_{24}\right)$ & 98.3 & 101.7 & 80.0 & 125.0 \\
\hline
\end{tabular}

Table 4: Confidence intervals (90\%) of the relevant pharmacokinetic parameters for the decision of bioequivalence.

\begin{tabular}{|c|c|c|}
\hline Adverse event & $\begin{array}{c}\text { Formulation A } \\
\mathbf{N = 3 6}\end{array}$ & $\begin{array}{c}\text { Formulation B } \\
\mathbf{N = 3 5}\end{array}$ \\
\hline Systemic events \\
\hline Arterial hypertension & $2(5.6 \%)$ & $3(8.6 \%)$ \\
\hline Headache & $2(5.6 \%)$ & $2(5.7 \%)$ \\
\hline Acidity & $1(2.8 \%)$ & - \\
\hline Pyrosis & $1(2.8 \%)$ & - \\
\hline Abdominal discomfort & - & $1(2.9 \%)$ \\
\hline Flu-like syndrome & $1(2.8 \%)$ & - \\
\hline Acute gastroenteritis & $1(2.8 \%)$ & - \\
\hline Tachycardia & - & $1(2.9 \%)$ \\
\hline Diarrhea & - & $1(2.9 \%)$ \\
\hline & $3(8.3 \%)$ & $1(2.9 \%)$ \\
\hline Laboratory alterations & $2(5.7 \%)$ \\
\hline Urea increase & $2(5.6 \%)$ & - \\
\hline Cholesterol increase & $2(5.6 \%)$ & - \\
\hline Glycemia increase & $1(2.8 \%)$ & - \\
\hline Bilirubin increase & $1(2.8 \%)$ & - \\
\hline Decrease in total proteins & $1(2.8 \%)$ & $1(2.9 \%)$ \\
\hline Thrombocytopenia & - & $1(2.9 \%)$ \\
\hline Hemoglobin increase & - & $1(2.9 \%)$ \\
\hline Leukopenia & - & $1(2.9 \%)$ \\
\hline Creatinine increase & - & \\
\hline
\end{tabular}

Data are presented as number of individuals with each adverse event $(\%)$

"Reference values applied: ALT: M $41 \mathrm{U} / \mathrm{L}, \mathrm{W}>33 \mathrm{U} / \mathrm{L} ; \mathrm{AST}$ : $\mathrm{M}>40 \mathrm{U} / \mathrm{L}, \mathrm{W}>32$

U/L; GGT: $M>60 \mathrm{U} / \mathrm{L}, \mathrm{W}>40 \mathrm{U} / \mathrm{L}$; urea: $2.76-8.07 \mathrm{mmol} / \mathrm{L}$; cholesterol: $<5.2$ $\mathrm{mmol} / \mathrm{L}$; glycemia: 4.11-5.89 mmol/L; total bilirubin: $<21 \mu \mathrm{mol} / \mathrm{L}$; total proteins: 66 $87 \mathrm{~g} / \mathrm{L}$; platelet counts <150 x10\%/L; Hgb: M: 130 - $175 \mathrm{~g} / \mathrm{L}, \mathrm{W}: 120-165 \mathrm{~g} / \mathrm{L}$; Total leukocytes: 4.5 - $11 \times 10^{9} / \mathrm{L}$; creatinine: M: $62-10^{6} \mu \mathrm{mol} / \mathrm{L}, \mathrm{W}: 44-80 \mu \mathrm{mol} / \mathrm{L}$.

Table 5: Frequency of adverse events during the study.

and malaise. The affected subject interrupted the treatment before the second period but he remained hospitalized during it in order to control this event. The number of events probably or possibly caused by the formulations rounded $70 \%$; the rest of them were not related. All of the events were well solved, most of them without therapeutic intervention.

No significant differences were found between the formulations regarding vital signs and clinical laboratory measurements, whose average values remained within normal ranges (data non-shown).

\section{Discussion}

The trial design (randomization, double blinding, crossover, washout period), population and statistical analysis complied with international guidelines for bioequivalence trials $[10,11]$. The facts that more than $80 \%$ of the $\mathrm{AUC}_{\text {inf }}$ could be easily covered by the $\mathrm{AUC}_{24}$ obtained and that there was no residual effect on the second period diclofenac sodium concentrations indicate that internal validity of the results was high. The selected dose, similar to other authors, was adequate, since plasma levels were well detected and the treatment was quite well tolerated. The crossover design is usually used in this kind of study. It has more statistical power to detect differences. The use of double blinding reduces the effect of the expectations of the investigator, analysts and statisticians as well as the subject under investigation.

\begin{tabular}{|c|c|c|c|}
\hline Characteristic & Classification & Formulation A & Formulation B \\
\hline \multirow{2}{*}{ Number of events } & $20(52.6 \%)$ & $18(47.4 \%)$ \\
\hline \multirow{2}{*}{ Severity } & Non-severe & $20(100 \%)$ & $18(100 \%)$ \\
\hline \multirow{2}{*}{ Causality } & Mild & $16(80.0 \%)$ & $18(100 \%)$ \\
\cline { 2 - 4 } & Moderate & $4(20.0 \%)$ & - \\
\cline { 2 - 4 } & Probable & $9(45.0 \%)$ & $8(44.4 \%)$ \\
\cline { 2 - 4 } & Possible & $5(25.0 \%)$ & $4(22.2 \%)$ \\
\hline \multirow{2}{*}{ Conduct } & Not related & $6(30.0 \%)$ & $6(33.3 \%)$ \\
\cline { 2 - 4 } & Pharmacotherapy & $3(15.0 \%)$ & $2(11.1 \%)$ \\
\hline Result & Observational & $17(85.0 \%)$ & $16(88.9 \%)$ \\
\hline
\end{tabular}

Data are reported as number of events (\%).

Table 6: Characterization of the adverse events registered.

Both formulations' pharmacokinetics was highly similar. Differences in means or medians did not exceed 3\% for any parameter and dispersions were also very similar, which resulted in closer $90 \% \mathrm{CI}$ for the ratio between formulations with the parameters $C_{\text {max }}$ and $A C_{24}$. Only differences were detected due to intra or inter-subject variability, not to the formulations. A major sample size is recommended for drugs with a high individual variability in their main pharmacokinetic parameters such as diclofenac sodium [12].

Plasma levels of diclofenac sodium were detected until 12 hours after administration. However, the peak was obtained at least two hours before to that reported for the slow-release formulation $[4,13,14]$. The mean terminal half-life was around 2.3 hours, somewhat higher than that reported after single oral dose, which ranged between 1-2 hrs (mean: $1.8 \mathrm{~h}$ ) [4].

Both formulations also showed a very similar safety profile being well tolerated. Most of the events were mild, and two of the four moderate events, flu-like syndrome and acute gastroenteritis, were not-related to the studied formulations. Taking into account that the population was healthy volunteers, the adverse events can have some degree of causality with the formulations administered.

The adverse events observed were in correspondence with the adverse reaction profile reported for the reference formulation. Reactions, such as gastrointestinal and increase in blood pressure are described for NSAIDs, especially propionic acid derivatives $[4,13]$. The subject with acute gastroenteritis constituted a withdrawal from the study due to constitutional symptoms such as vomiting and diarrhea, which can alter the normal physiology of the gastrointestinal tract and therefore interfering with the drug absorption. On the other hand, the reversible increase of transaminases was within $5-15 \%$ of incidence reported in the literature [4,14-16].

The comparable pharmacokinetics and safety data of the newly developed prolonged-release diclofenac sodium preparation can be the basis for its further clinical development. Its introduction in the national health system will certainly have a significant impact on the health care. 
Citation: González-Delgado CA, Padrón-Yaquis AS, Jiménez-Rodríguez D, Cazanave-Guarnaluce D, Alejo-Cisneros PL, et al. (2017) Bioequivalence of Two Prolonged-Release Diclofenac Sodium Formulations in Healthy Volunteers: A Randomized, Crossover, Double-Blind Study. J Bioequiv Availab 9: 555-560. doi: 10.4172/jbb.1000361

\section{Conclusions}

The diclofenac sodium retard test formulation demonstrated similarity in its pharmacokinetic and biological safety properties with the reference formulation Voltaren Retard'. Efficacy trials can be carried out to confirm clinical similarity.

\section{Acknowledgment}

The authors wish to thank Lourdes Olivera, Armando Correa, Reinaldo Hevia Víctor Rodríguez and José Delgado for their participation in the clinical work. Alexey García for manuscript review, and especially to the thirty-six young people who served as volunteers. The study was financed by the Centre for Pharmaceutical Research and Development, Havana, Cuba (formulations, reagents). The Ministry of Public Health of Cuba supported the clinical trial (hospital facilities and genera medical care of the volunteers as in-patients).

\section{Competing Interests}

Authors ASPY, DJR, DCG, PLAC, TFC, MBS and IGG are employees of the Centre for Pharmaceutical Research and Development (CIDEM), Havana, Cuba, where national prolonged-release diclofenac sodium formulation was developed. The rest of the authors have no competing interests concerning this paper.

\section{Authors' Contributions}

CAGD wrote the clinical protocol, he was the main investigator and analyzed the results. ASPY participated in the design and coordination of the study, analysis of the results as well as the manuscript writing. DJR and TFC monitored the study and participated in the analysis of the results. DCG, PLAC and MBS carried out HPLC determinations. ADM, SPR and LBV took part in the subject recruitment management, clinical examinations and follow-up. AMT processed blood samples and coordinated clinical laboratory evaluations. IGG analyzed the results and wrote the manuscript draft. All authors read and approved the final manuscript.

\section{References}

1. Brogden RN, Heel RC, Pakes GE, Speight TM, Avery GS (1980) Diclofenac sodium: a review of its pharmacological properties and therapeutic use in rheumatic diseases and pain of varying origin. Drugs 20: 24-48.

2. Inflammatory disease and the role of Voltaren (diclofenac sodium). Proceedings of a symposium, May 14-15, 1985, Tahiti. Am J Med 80: 1-87.

3. Rang HP, Dale MM, Ritter JM (2007) Anti-inflammatory and immunosuppressant drugs. In: Flower RJ, editor. Rang and Dales Pharmacology. 6th Edition. China: Elsevier; pp: 226-245.
4. Voltaren Retard® SR (diclofenac sodium), $100 \mathrm{mg}$ Slow-Release Tablets Product monograph (2016). Novartis Pharmaceuticals.

5. European Medicines Agency, Committee for Medicinal Products for Human Use (CHMP). Guideline on the pharmacokinetic and clinical evaluation of modified release dosage forms (EMA/CHMP/EWP/280/96 Rev1). London, 21 February 2013.

6. Common Terminology Criteria for Adverse Events (CTCAE), Version 4.0, Published: May 28, 2009 (v4.03: June 14, 2010), DCTD, NCI, NIH, DHHS.

7. The use of the WHO-UMC system for standardized case causality assessment

8. Grizzle JE (1965) The two period change-over design and its use in clinical trials. Biometrics 21: 467-480.

9. Steinijans VW, Hauschke D (1990) Update on the statistical analysis of bioequivalence studies. Int J Clin Pharmacol Ther Toxicol 28: 105-110.

10. U.S. Department of Health and Human Services, Food and Drug Administration, Center for Drug Evaluation and Research (CDER), Guidance for Industry: Statistical Approaches to Establishing Bioequivalence, January 2001: 1-45.

11. European Agency for the Evaluation of Medicinal Products. Committee for Proprietary Medicinal Products (COMP). Guidance on the Investigation of Bioequivalence. London 2010: 1-27.

12. Silva LC, Simões IG, Lerner FE, Belém GR, de Moraes ME, et al. (1999) Comparative bioavailability of two different diclofenac formulations in healthy volunteers. Arzneimittelforschung 49: 920-924.

13. Raz I, Hussein Z, Samara E, Ben-David J (1988) Comparative pharmacokinetic analysis of a novel sustained-release dosage form of diclofenac sodium in healthy subjects. Int J Clin Pharmacol Ther Toxicol 26: 246-248.

14. Hasan MM, Najib NM, Muti H (1993) A comparative bioavailability study on two sustained-release formulations of diclofenac sodium following a single dose administration. Int J Clin Pharmacol Ther Toxicol 31: 387-391.

15. Figueras A, Capellà D, Castel JM, Laorte JR (1994) Spontaneous reporting of adverse drug reactions to non-steroidal anti-inflammatory drugs. A report from the Spanish System of Pharmacovigilance, including an early analysis of topical and enteric-coated formulations. Eur J Clin Pharmacol 47: 297-303.

16. Banks AT, Zimmerman HJ, Ishak KG, Harter JG (1995) Diclofenac-associated hepatotoxicity: analysis of 180 cases reported to the Food and Drug Administration as adverse reactions. Hepatology 22: 820-827. 